
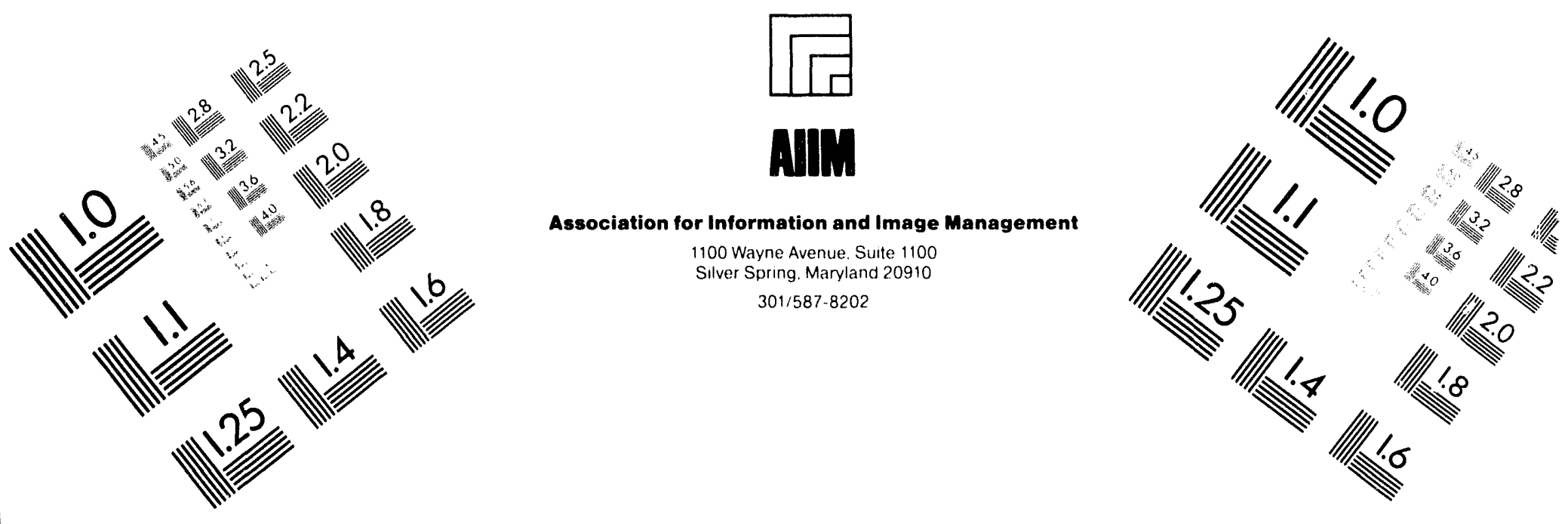

Centimeter

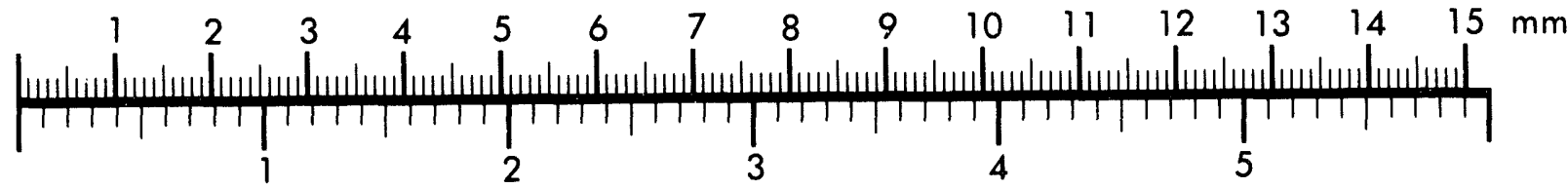
Inches
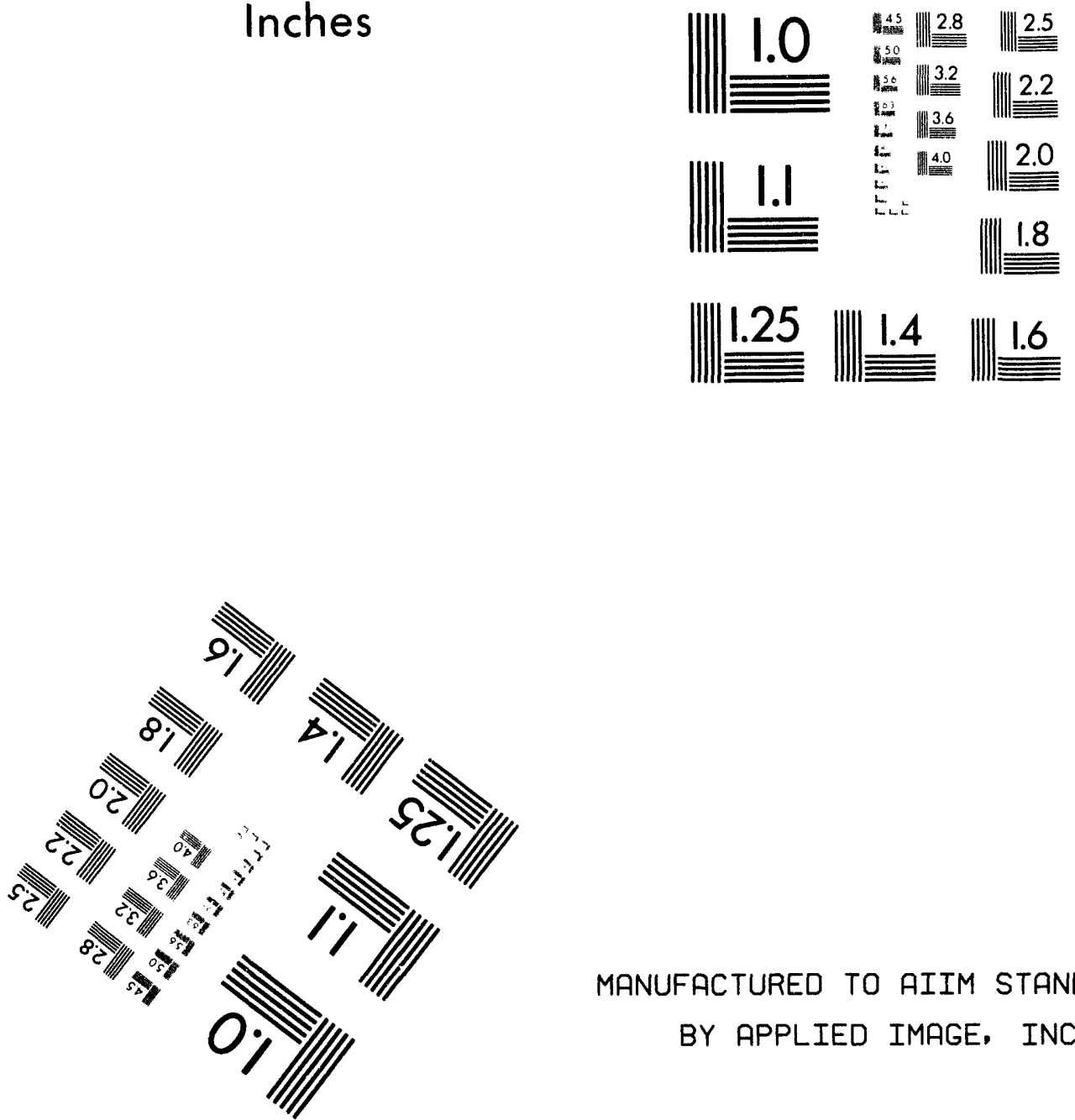

MANUFACTURED TO AIIM STANDARDS

BY APPLIED IMAGE, INC.

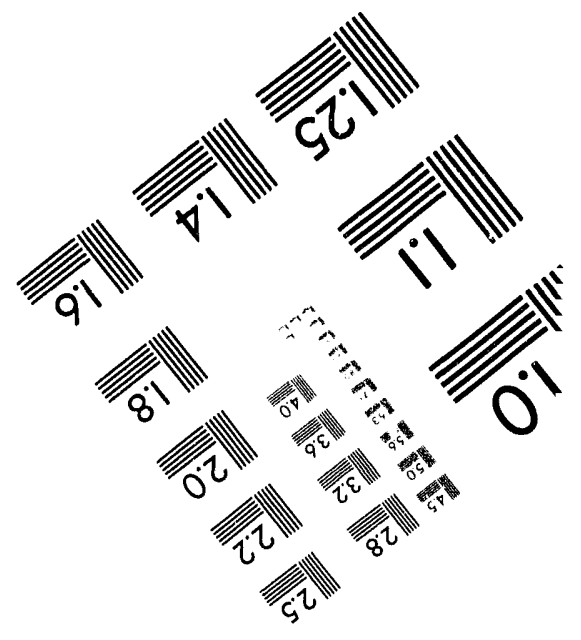



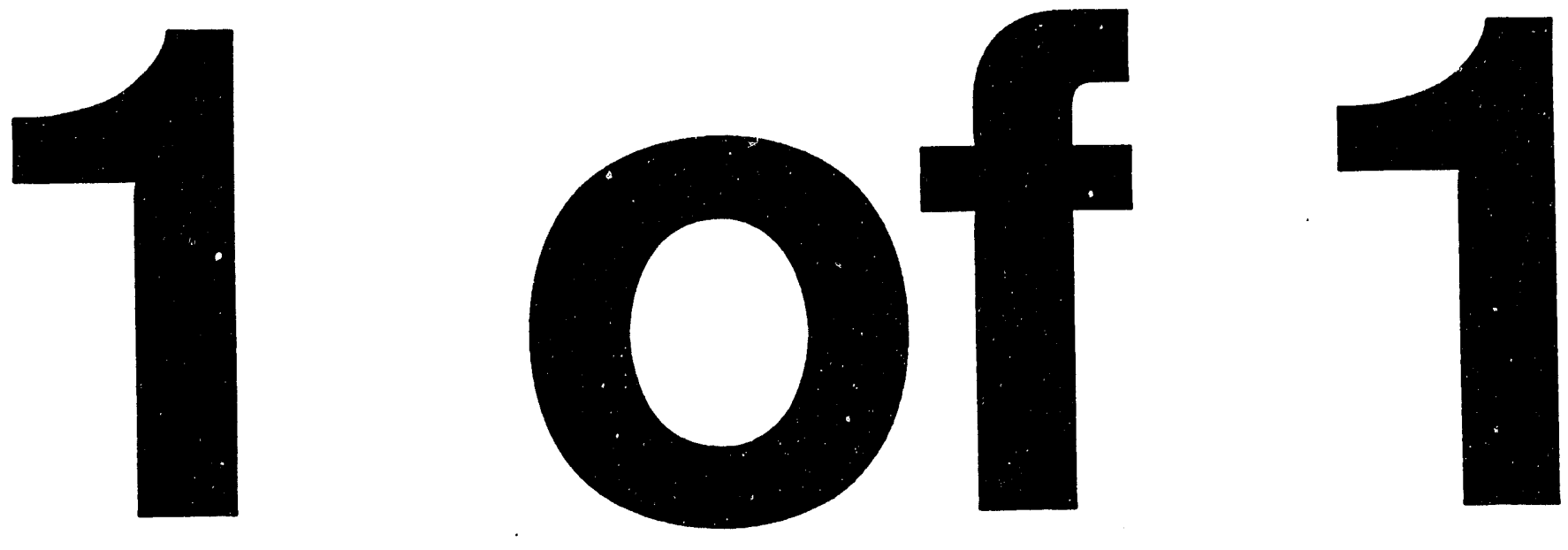


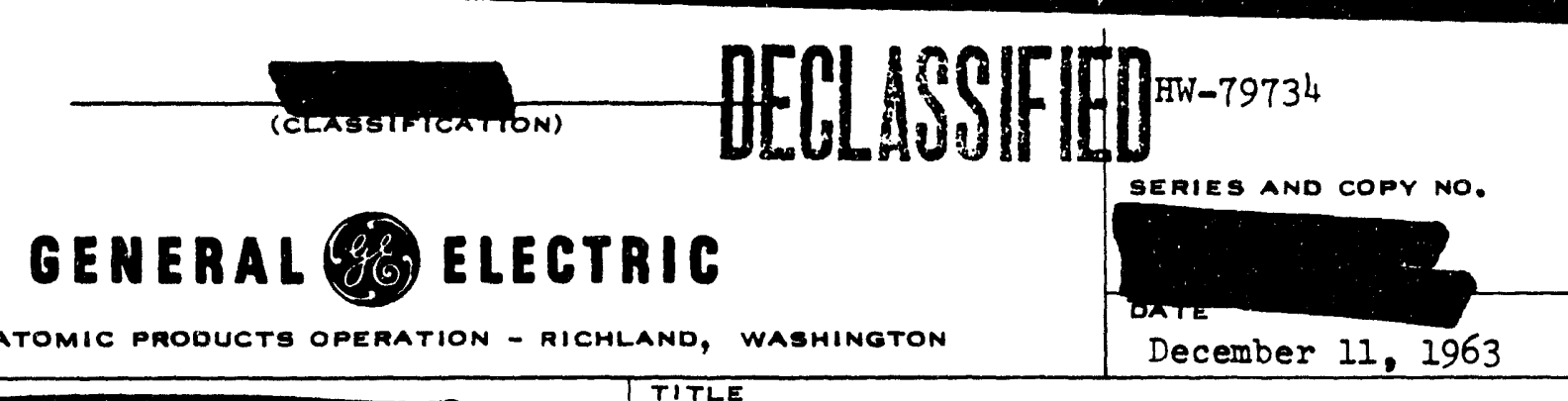

HANFORD ATOMIC PRODUCTS OPERATION - RICHLAND, WASHINGTON

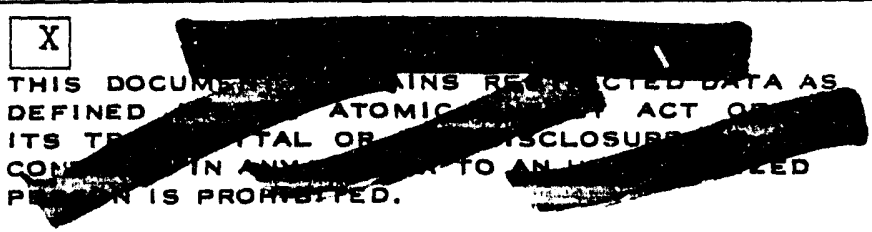

LONG-TERM NEUTRON ACTIVATION PRODUCTS OF NICKEL-58

$\square$ OTHEIA ofFICIAL CLASSIFIED INFORMATION THIS MATERIAL CONTAINS INFORMATION AFFECTING THE NATIONAL DEFENSE OF THE UNITED STATES WITHIN THE MEANING OF THE ESPIONAGE LAWS. TITLE 18, U. S.C., SECS. TOS AND 794, THE TRANSMISSION OR REVILATION OF WHICH IN ANY MANNER TO AN UNAUTHORIZED PERSON IS PROHIBITED BY LAW.

\begin{tabular}{|l|l}
\hline AUTHOR & ISSUING FILE \\
W. Co Morgan &
\end{tabular}

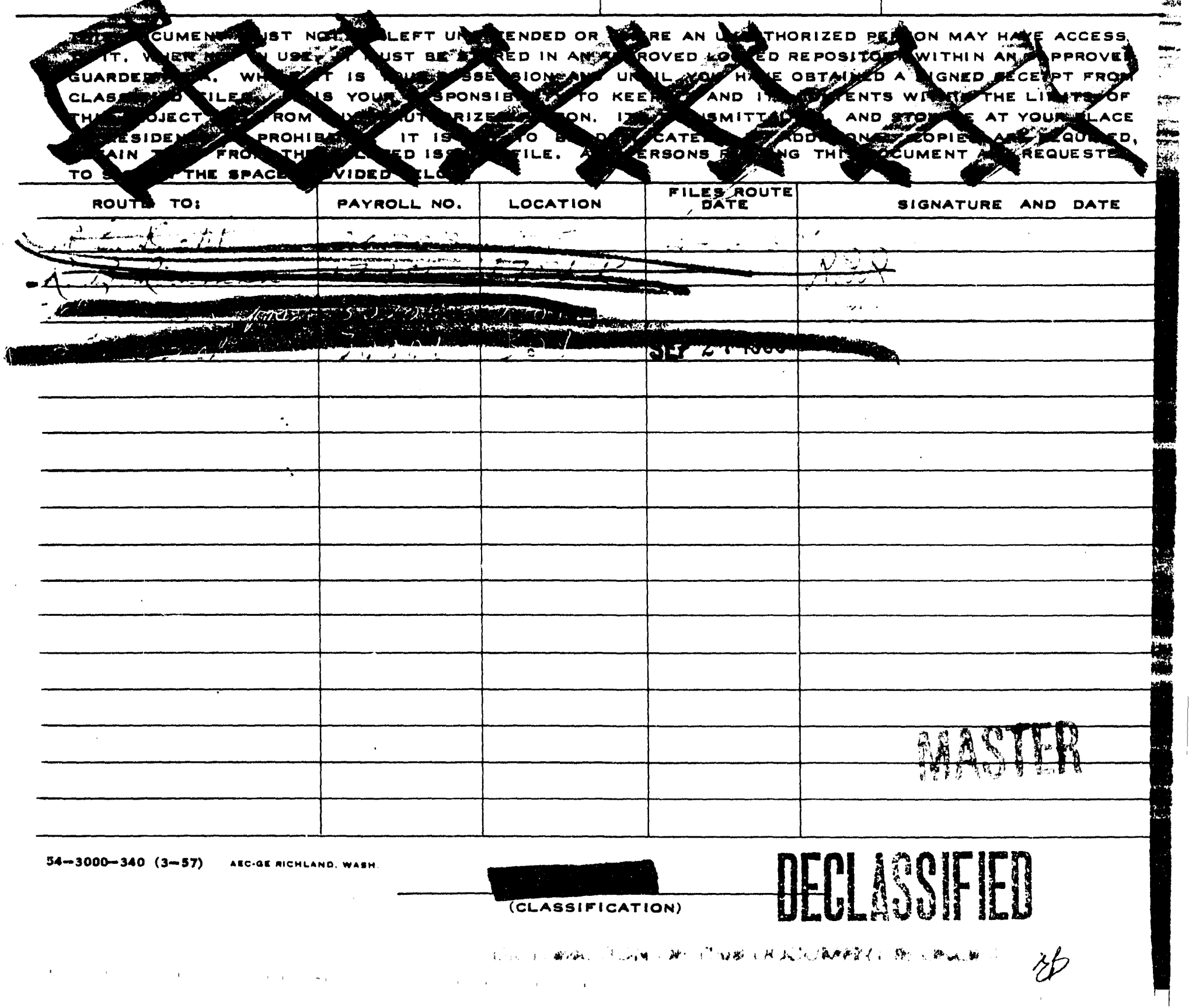


This document classified

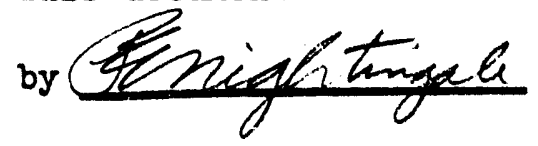

Cresification Conosind and Chanoed To

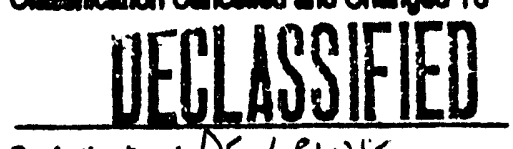

Oy Authorty of DS LEWIS

CG-PR-2, 4-4-94

Britanson 4-16-94

verifiod By Aerri inaley, 4-18-44.

LONG-TERM NEUTRON ACTIVATION PRODUCTS
This document consists of

2 pages.

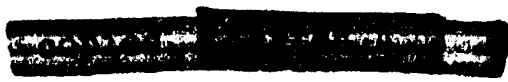

\section{OF NICKEL-58}

W. Co Morgan
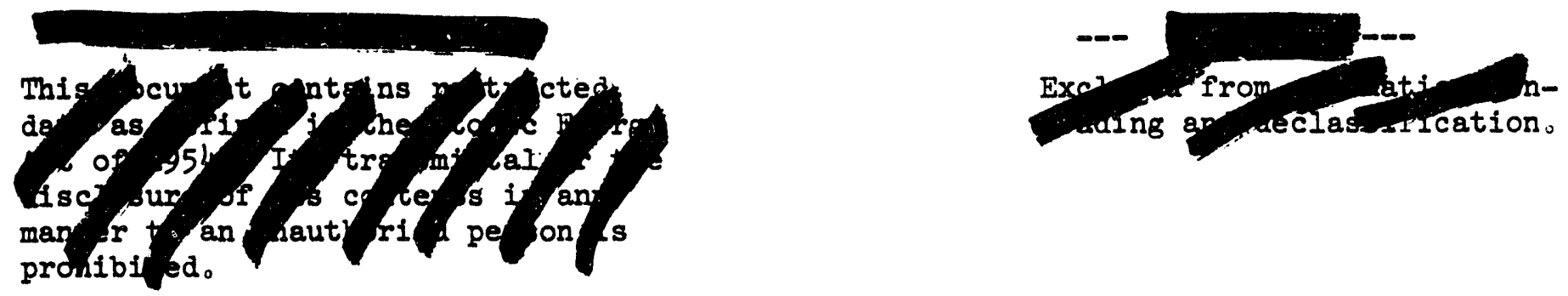

- Distribution -

1. S。 H。 Bush

2. R。E。Dahl

3. Jo Mo Fox, Jr。

4. P。 H。 Hutton

5. P。C。Jerman

6. W。N.Koop

7。 Wo C。 Morgan

8. R。 E。 Nightingale
9. Mn In Smith

10. F。W.Van Wormer

11。 E。 E。 Voiland

12. H。 Ho Yoshikawa

13. 300 File

14. Record Center

15.-20。 Extras

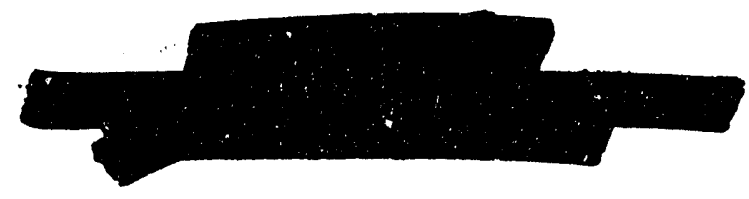




\section{LONG-TERM NEUTRON ACTIVATION PRODUCTS OF NICKEL-58}

\section{Introduction}

Certain advantages, such as higher strength at elevated temperature, have led to the use of alloys containing large percentages of nickel as a replacement for aluminum components. One example is the inconel sheathing of control rods for the Hanford reactors. Since some of these components may remain in a reactor several years prior to removal, the neutronactivation products resulting from multiple chain reactions may become important ${ }^{l}$ in determining the radiation exposure levels at discharge. This paper outlines one of the activation chains which may contribute, significantly to the $\gamma$-activity. Equations are developed from which the corcentrations of the product isotopes emanating from nickel-58 can be calculated。 "Best values" of the parameters used in these calculations are tabulated, and the conversion from isotope concentration to $\gamma$-dose rate is outlined.

\section{Derivation of Equations}

The long-term activation chain of nickel-58 is outlined as follows:

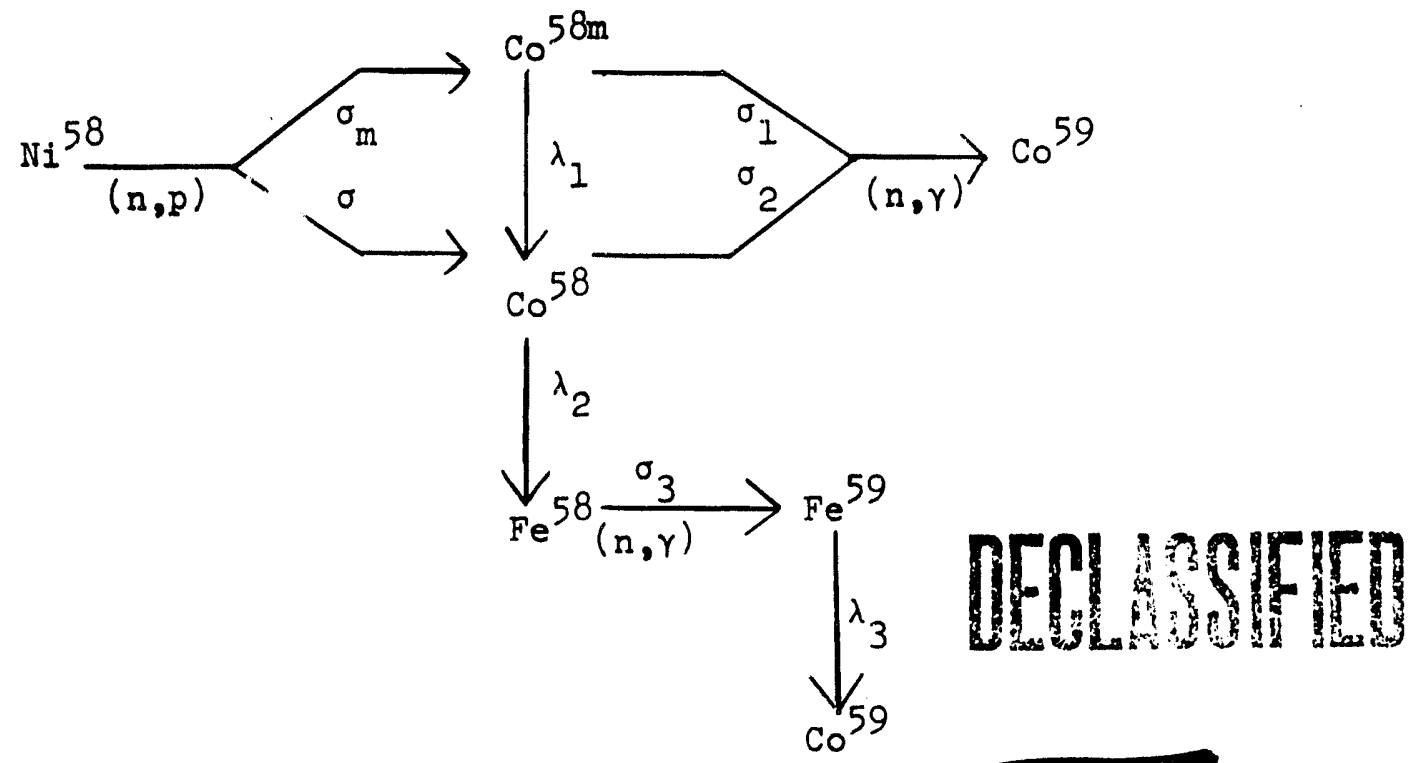




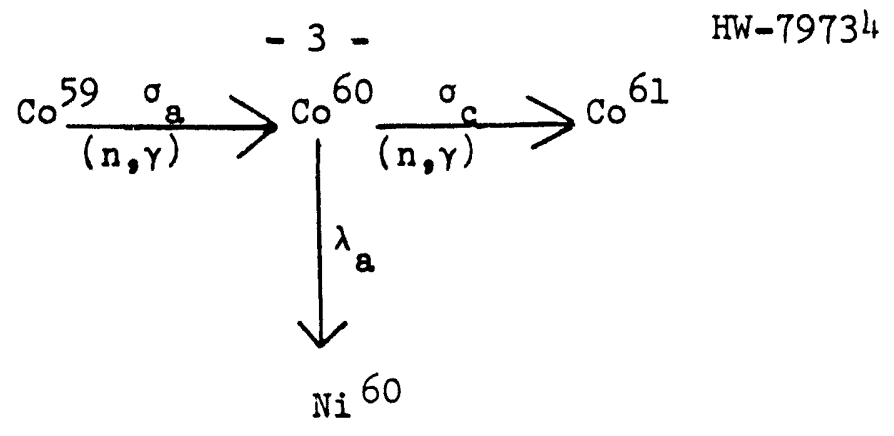

Where: $\sigma, \sigma_{m}, \sigma_{l}$, etco are activation cross sections, and $\lambda_{1}, \lambda_{a}$, etc。 are decay constants.

The concentrations of the activation products, emanaing from the original $\mathrm{Ni}^{58}$, can be described by the following set of differential equations:

$$
\begin{aligned}
& \frac{d\left[\mathrm{Co}^{58 \mathrm{~m}}\right]}{d t}=\left[\mathrm{Ni}^{58}\right] \sigma_{\mathrm{m}} \phi_{\mathrm{f}}-\left[\mathrm{Co}^{58 \mathrm{~m}}\right]\left(\lambda_{1}+\sigma_{1} \phi\right) \\
& \frac{d\left[\mathrm{Co}^{58}\right]}{d t}=\left[\mathrm{Ni}^{58}\right] \sigma \phi_{f}+\left[\mathrm{Co}^{58 \mathrm{~m}}\right] \lambda_{1}-\left[\mathrm{Co}^{58}\right]\left(\lambda_{2}+\sigma_{2} \phi\right) \\
& \frac{\mathrm{d}\left[\mathrm{Fe}^{58}\right]}{\mathrm{dt}}=\left[\mathrm{Co}^{58}\right] \lambda_{2}-\left[\mathrm{Fe}^{58}\right] \sigma_{3} \phi \\
& \frac{\mathrm{d}\left[\mathrm{Fe}^{59}\right]}{\mathrm{dt}}=\left[\mathrm{Fe}^{58}\right] \sigma_{3} \phi-\left[\mathrm{Fe}^{59 \cdot}\right] \lambda_{3} \\
& \frac{d\left[\mathrm{Co}^{59}\right]}{\mathrm{dt}}=\left(\left[\mathrm{Co}^{58 \mathrm{~m}}\right] \sigma_{1}+\left[\mathrm{Co}^{58}\right] \sigma_{2}\right) \phi+\left[\mathrm{Fe}^{59}\right] \lambda_{3}-\left[\mathrm{Co}^{59}\right] \sigma_{\mathrm{a}} \phi \\
& \frac{d\left[\mathrm{Co}^{60}\right]}{d t}=\left[\mathrm{Co}^{59}\right] \sigma_{\mathrm{a}} \phi-\left[\mathrm{Co}^{60}\right]\left(\lambda_{\mathrm{a}}+\sigma_{c} \phi\right) \\
& \text { Where, } \phi_{f}=\text { Fast neutron flux } \\
& \phi=\text { Thermal neutron flux, and } \\
& {\left[\mathrm{Ni}^{58}\right] \text { indicates the concentration of the enclosed }} \\
& \text { isotope, } \mathrm{Ni}^{58} \text {, etc。 } \\
& {\left[\mathrm{Ni}^{58}\right]=\frac{\mathrm{CP} \mathrm{N}_{\mathrm{O}}}{10^{4} \mathrm{~A}}} \\
& C=\text { per cent concentration of nickel in the alloy。 }
\end{aligned}
$$

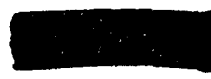




$$
\begin{aligned}
\mathrm{P} & =\text { per cent abundance of } \mathrm{Ni}^{58} \text { in nickel } \\
N_{0} & =\text { Avogadro's Number, number of atoms per gram mole } \\
A & =\text { Atomic Weight of nickel }
\end{aligned}
$$

Thermal activation, not shown in the preceding activation scheme, removes only about 0.8 per cent of the $\mathrm{Ni}^{58}$ per year at the highest flux positions in $\mathrm{K}$ reactor; therefore, it may be ignored for most calculations, or a simple reduction in $\left[\mathrm{Ni}^{58}\right]$ can be made to compensate for the average reduction over the exposure range of interest.

The solution to equation 1 can be written:

$$
\left[\mathrm{Co}^{58 \mathrm{~m}}\right]=\frac{\left[\mathrm{Ni}{ }^{58}\right] \sigma_{\mathrm{m}} \phi_{\mathrm{f}}\left[1-\mathrm{e}^{-\left(\lambda_{1}+\sigma_{1} \phi\right) t}\right]}{\left(\lambda_{1}+\sigma_{1} \phi\right)}
$$

For most positions in the Hanford reactors, equation (7a) reduces, for $t$ more than 2 days, to:

$$
\left[\mathrm{Co}^{58 \mathrm{~m}}\right]=\frac{\left[\mathrm{Ni}^{58}\right] \sigma_{\mathrm{m}} \phi_{\mathrm{f}}}{\left(\lambda_{1}+\sigma_{1} \phi\right)}
$$

which can be written more compactly,

$$
\begin{gathered}
{\left[\mathrm{Co}^{58 \mathrm{~m}}\right]=\alpha \sigma_{\mathrm{m}}} \\
\text { Where, } \alpha=\frac{\left[\mathrm{Ni}^{58}\right]_{\phi_{f}}}{\left(\lambda_{1}+\sigma_{1} \phi\right)}
\end{gathered}
$$

The solution to equation 2 is given by:

$$
\begin{array}{r}
{\left[\mathrm{Co}^{58}\right]=\left[\mathrm{Ni}^{58}\right]_{\mathrm{f}}\left\{\left(\frac{1}{\lambda_{2}+{ }_{2} \phi}\right)\left(\frac{\lambda_{1} \sigma_{m}}{\lambda_{1}+{ }_{1} \phi}+\sigma\right)\left[1-\mathrm{e}^{-\left(\lambda_{2}+\sigma_{2} \phi\right) t}\right]\right.} \\
\left.+\left(\frac{\lambda_{1} \sigma_{m}}{\lambda_{1}+\sigma_{1} \phi}\right)\left[\frac{1}{\lambda_{1}-\lambda_{2}+\left(\sigma_{1}-\sigma_{2}\right) \phi}\right]\left[e^{-\left(\lambda_{1}+\sigma_{1} \phi\right) t}-e^{-\left(\lambda_{2}+\sigma_{2} \phi\right) t}\right]\right\}
\end{array}
$$


For most positions in the Hanford reactors, equation $(8 a)$ reduces, for $t$ more than 15 days, to: .

$$
\left[\mathrm{Co}^{58}\right]=\frac{\left[\mathrm{Ni}^{58}\right] \phi_{f}}{\left(\lambda_{2}+\sigma_{2} \phi\right)}\left(\frac{\lambda_{1} \sigma_{\mathrm{m}}}{\lambda_{1}+\sigma_{2} \phi}+\sigma\right)\left[1-\mathrm{e}^{-\left(\lambda_{2}+\sigma_{2} \phi\right) t}\right]
$$

or, written more compactly,

$$
\begin{aligned}
& {\left[\mathrm{Co}^{58}\right]=\beta\left[1-\mathrm{e}^{-\left(\lambda_{2}+\sigma_{2} \phi\right) \mathrm{t}}\right]} \\
& \text { Where, } \quad \beta=\frac{\left[\mathrm{Ni}{ }^{58}\right] \phi_{f}}{\left(\lambda_{2}+\sigma_{2} \phi\right)}\left(\frac{\lambda_{1} \sigma_{\mathrm{m}}}{\lambda_{1}+\sigma_{1} \phi}+\sigma\right)=\alpha\left[\frac{\lambda_{1} \sigma_{\mathrm{m}}+\sigma_{1}\left(\lambda_{1}+\sigma_{1} \phi\right)}{\lambda_{2}+\sigma_{2} \phi}\right]
\end{aligned}
$$

Substituting (8) into equation 5 , the solution reduces to:

$$
\left[\mathrm{Fe}^{58}\right]=\beta \frac{\lambda_{2}}{\sigma_{3} \phi}\left(1-\mathrm{e}^{-\sigma_{3} \phi t}\right)
$$

Likewise the solution to equation 6 reduces to:

$$
\left[\mathrm{Fe}^{59}\right]=\beta \frac{\lambda_{2}}{\lambda_{3}}\left(1-\mathrm{e}^{-\sigma_{3} \phi t}\right)
$$

The solution to equation 7 can be written:

$$
\begin{aligned}
& {\left[\mathrm{Co}^{59}\right]=\left[\frac{\alpha \sigma_{m} \sigma_{1}}{\sigma_{a}}+\frac{\beta \sigma_{2}}{\sigma_{a}}+\frac{\beta \lambda_{2}}{\sigma_{a} \phi}\right]\left(1-e^{-\sigma_{a} \phi t}\right)-\left[\frac{\beta \sigma_{2} \phi}{\lambda_{2}+\left(\sigma_{2}-\sigma_{a}\right)_{\phi}}\right] .} \\
& \left.\left[e^{-\left(\lambda_{2}+\sigma_{2} \phi\right) t}-e^{-\sigma_{a} \phi t}\right]-\left[\frac{\beta \lambda_{2}}{\left(\sigma_{a}-\sigma_{3}\right) \phi} \mid e^{-\sigma_{3} \phi t}-e^{-\sigma_{a} \phi t}\right)\right]
\end{aligned}
$$

or, more compactly,

$$
\left.\left[c^{59}\right]=\left(\frac{\gamma}{\sigma_{a} \phi}\right)\left(1-e^{-\sigma_{a} \phi t}\right)-\delta\left[e^{-\left(\lambda 2^{\left.+\sigma_{2} \phi\right) t}\right.}-e^{-\sigma_{a} \phi t}\right]-\frac{\varepsilon}{\phi} / e^{-\sigma_{3} \phi t}-e^{-\sigma_{a} \phi t}\right)
$$




$$
\text { Where, } \begin{aligned}
\gamma & =\left[\alpha \sigma_{m} \sigma_{1} \phi+\beta\left(\lambda_{2}+\sigma_{2} \phi\right)\right] \\
\delta & =\frac{\beta \sigma_{2} \phi}{\lambda_{2}+\left(\sigma_{2}-\sigma_{a}\right) \phi} \\
\varepsilon & =\frac{\beta \lambda_{2}}{\left(\sigma_{a}-\sigma_{3}\right)}
\end{aligned}
$$

The solution to equation 6 can be written:

$$
\begin{aligned}
& {\left[c 0^{60}\right]=\left(\gamma+\delta \sigma_{a}+\varepsilon \sigma_{a}\right)\left[\frac{e^{-\sigma_{a} \phi t}-e^{-\left(\lambda_{a}+\sigma_{c} \phi\right) t}}{\lambda_{a}+\left(\sigma_{c}-\sigma_{a}\right) \phi}\right]+\gamma\left[\frac{\left.1-e^{-\lambda} a c_{c} \phi\right) t}{\lambda_{a}+\sigma_{c} \phi}\right]} \\
& +\delta \sigma_{a} \phi\left[\frac{e^{-\left(\lambda_{a}+\sigma_{c} \phi\right) t}-e^{-\left(\lambda_{2}+\sigma_{2} \phi\right) t}}{\lambda_{a}-\lambda_{2}+\left(\sigma_{c}-\sigma_{2}\right) \phi}\right]-\varepsilon \sigma_{a}\left[\frac{e^{-\sigma_{3} \phi t}-e^{-\left(\lambda_{a}+\sigma_{c} \phi\right) t}}{\lambda_{a}+\left(\sigma_{c}-\sigma_{3}\right) \phi}\right]
\end{aligned}
$$

\section{Notes on Numerical Evaluation}

It is suggested that the exposure $(\phi t)$ and neutron fluxes ( $\phi$ and $\phi_{f}$ ) be entered in the forms $[(n v t / M w d / A t)$ average $x$ (Mwd́/At) measured $]$ and [invt/Mwd/At) average $\left.x(\text { Mw/At })_{\text {measured }}\right]$. Using this method, the calculations are not made obsolete by a change in power level, which changes the flux level but not the ratio of exposure per unit power. Mw/At can be routinely monitored; thus the activity can readily be calculated at any time.

Neutron exposures are dependent on position in the reactors. The fastneutron cross sections $(\bar{\sigma})$ are given in terms of the neutron spectrum ${ }^{2}$, and the neutron-flux energy range established by $\phi_{f}$ :

$$
\bar{\sigma}\left(E_{1}\right)=\frac{\int_{0}^{\infty} \phi(E) \sigma(E) d E}{\int_{E_{1}}^{\infty} \phi(E) d E}
$$




$$
-7-\quad H W-79734
$$

Where, $\bar{\sigma}\left(E_{1}\right)=$ the neutron activation cross section averaged over the reactor spectrum above energy $E_{1}$ 。

$\phi(E)=$ the neutron energy spectrum for the reactor。

$\sigma(E)=$ the neutron-activation cross section as a function of neutron energy.

The neutron exposures per Mwd/At and fast-neutron activation cross sections are listed in Table I. The numbers given are valid only for irradiations made in the equivalent of hot-test-hole positions of the two reactors. "Best values" of the other constants are also tabulated.

TABLE I。 "BEST VALUES" OF THE CONSTANTS

Symbol

$\frac{\phi}{\sqrt{w d / A t}}$

$\frac{\phi_{f}}{\text { Mrd/At }}$

$\sigma$

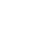

m Quantity

Value

Thermal exposure in:
$\mathrm{K}$ Reactor
C Reactor
other old reactors
$4.5 \times 10_{17}^{17} \mathrm{nvt} / \mathrm{Mwd} / \mathrm{At}$
$4.6 \times 10_{17}^{17} \mathrm{nvt} / \mathrm{Mwd} / \mathrm{At}$
$4.7 \times 10^{17} \mathrm{nvt} / \mathrm{Mwd} / \mathrm{At}$

Fast exposure ( $E>1.0 \mathrm{Mev})$ in:

$$
\begin{array}{ll}
\mathrm{K} \text { Reactor } & 4.6 \times 10^{16} \mathrm{nvt} / \mathrm{Mwd} / \mathrm{At} \\
\mathrm{C} \text { Reactor } & 3.5 \times 10^{16} \mathrm{nvt} / \mathrm{Mwd} / \mathrm{At}
\end{array}
$$

$\mathrm{Ni}^{58}(\mathrm{n}, \mathrm{p}) \mathrm{Co}^{58}$ activation

cross section for $\phi_{f}(E>1.0 \mathrm{Mev})$

in:
K Reactor
C Reactor
$7.4 \times 10^{-26} \mathrm{~cm}^{2}$
$7.3 \times 10^{-26} \mathrm{~cm}^{2}$

$\mathrm{Ni}^{58}(\mathrm{n}, \mathrm{p}) \mathrm{Co}^{58 \mathrm{~m}}$ activation

cross section for $\phi_{f}(E>1.0 \mathrm{Mev})$

in:

$\mathrm{K}$ Reactor

C Reactor
Ref。 
- Table I continued -

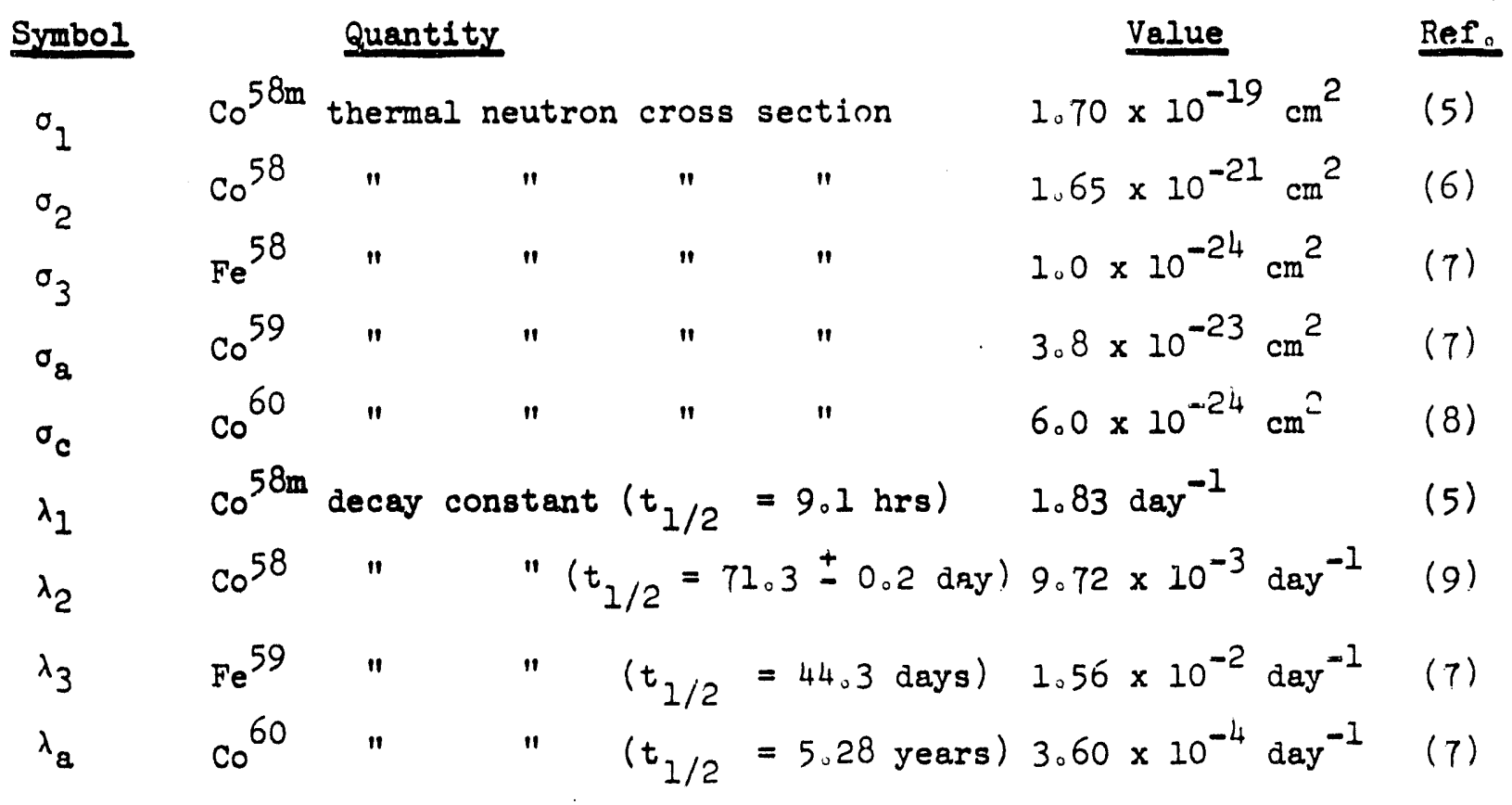

To compute the disintegration rate per unit of material from the concentrations of the isotopes calculated from the equations derived in the preceding section, multiply the concentration of each isotope by its decay constant and weight (in grams) of alloy per unit of material ( $i_{0} e_{\circ}:$ per foot, $100 \mathrm{gm}$, etrof of component)。The $r$-yield per disintegration ${ }^{10}$ for the product isotopes is listed in Table II.

\section{TABLE II。 $\gamma$-YIELDS}

\begin{tabular}{ccc} 
Isotope & Energy per $\gamma$ mev & $\begin{array}{c}\text { Average number of } \\
\gamma^{*} \text { s per disintegration }\end{array}$ \\
\cline { 2 - 2 }${ }^{60}$ & 1.17 & 1.00 \\
1.33 & 1.00 \\
$\mathrm{Co}^{58}$ & 0.81 & 1.00 \\
$\mathrm{Fe}^{59}$ & 1.29 & 0.46 \\
& 1.10 & 0.54
\end{tabular}


1. W. N. Koop, "Radiation Exposure from Inconel Horizontal Control Rods", HW-79528, November 8, 1963 (Secret)。

2. R。 E。 Dahl, "Methods Used to Calculate Neutron Exposures and Damage for Graphite Irradiation Studies", HW-79793, to be published。

3. Wo Co Morgan and Wo L。 Bunch, "Neutron Flux as a Function of Tube Power", HW-63991, February 22, 1960 (Secret).

4. Ho Ho Yoshikawa and W。 Co Morgan, "Neutron Fluxes in Hanford Irradiation Facilities, Interim Report No。 3", HW-76921, to be published。

5. Co H。 Hogg, L。 $D_{0}$ ! Weber and $E_{0} C_{0}$ Yates, "Thermal-Neutron Cross Sections of $C_{058}$ Isomers and the Effect on Fast Flux Measurements Using Nickel," Trans。Am。Nucl。Soc. 4 (2), p。271, 1961。

6. Co HoHogg $L_{0} D_{0}$ Weber and $E_{0} C_{0}$ Yates, "Thermal-Neutron Cross Sections of the Co58 Isomers and the Effect on Fast Flux Measurements Using Nickel," IDO-16744, June 18, 1962。

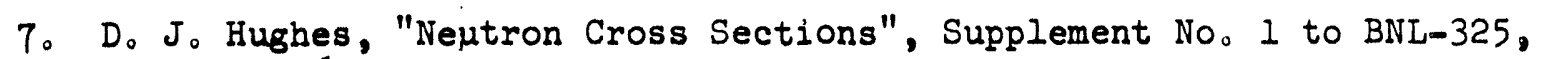
January 1960。

8. D. Jo Hughes, "Neutron Cross Section", BNL-325, July, 1958.

9. R。 $P_{0}$ Schuman, $M_{0} E_{0}$ Jones and $A_{0} C_{\text {q }}$ Mewherter, "Half-lives of $\mathrm{Ce}^{144}$. $\mathrm{Co} 5^{\circ}, \mathrm{Cr} 51, \mathrm{Fe}^{55}, \mathrm{Mn} 54, \mathrm{Pm}{ }^{147}, \mathrm{Ru}^{106}$, and $\mathrm{Sc} 46^{\prime}, " \mathrm{~J}$ Inorg, \& Nucl。Chem。, 3. p。106, 1956。

10. Do Strominger, $J \circ M_{0}$ Hollander, and $G_{0} T_{0}$ Seaborg, "Table of Isotopes", Rev。Mod。Phys。, 30 (2), p。 585, April 1958。 

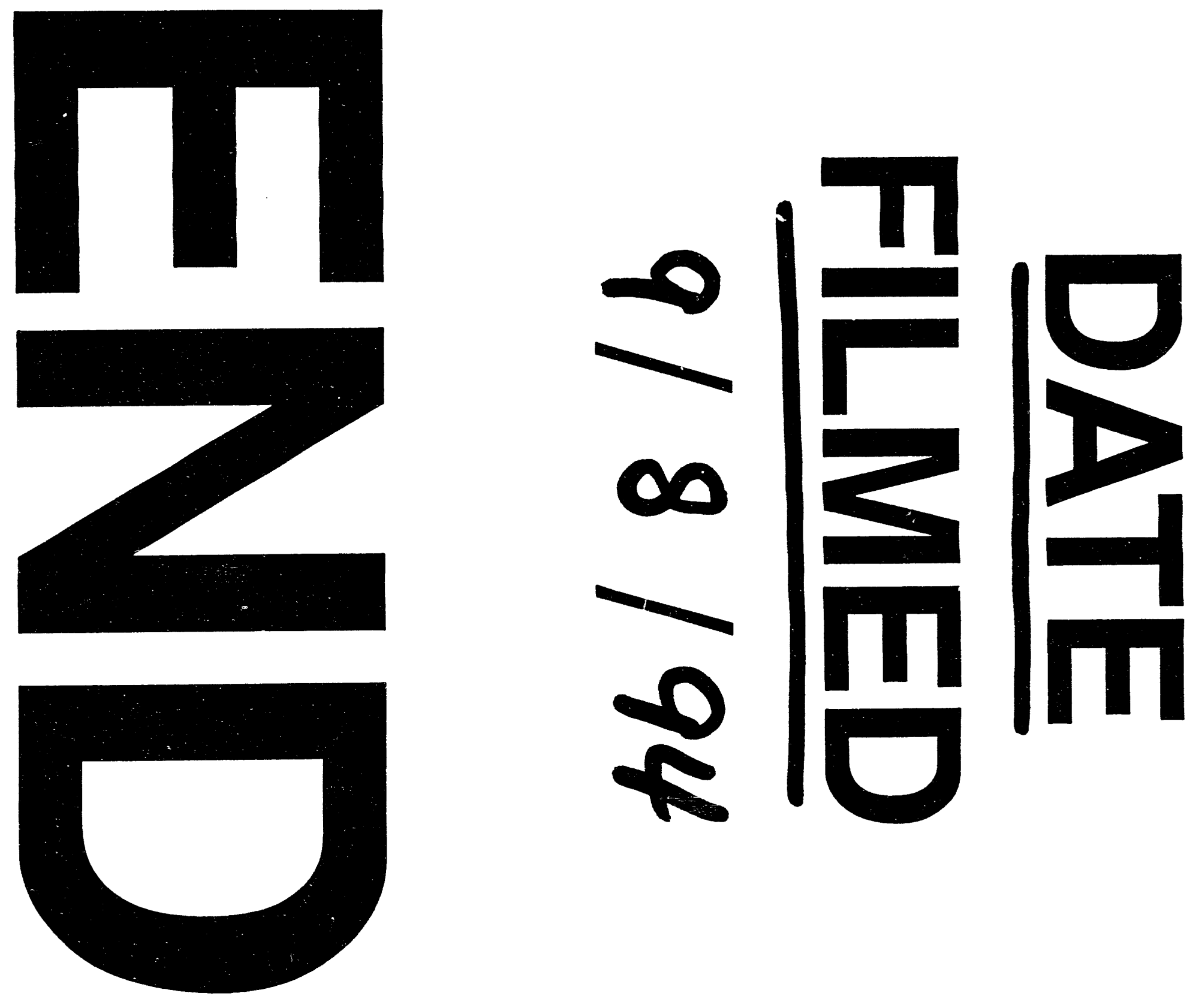